\title{
TRABALHOS DE CAMPO NAS DISCIPLINAS DE GEOLOGIA INTRODUTÓRIA: CURSOS DE GEOGRAFIA NO ESTADO DO PARANÁ
}

\author{
Fieldwork on the Courses of Introductory Geology: \\ Courses of Geography in the State of Paraná
}

\author{
Adalberto SCORTEGAGNA ${ }^{1}$
}

\begin{abstract}
RESUMO
A pesquisa busca analisar as atividades de campo na disciplina de Geologia Introdutória nos cursos de Geografia no Estado do Paraná. Os dados foram coletados por meio de entrevistas com os professores responsáveis pela disciplina, nas instituições de ensino que mantêm o curso de Geografia no Estado. A análise dos resultados possibilitou caracterizar a prática dos professores nas atividades de campo, desde a preparação até a execução, além de constatar as diferentes visões de ensino dos diferentes profissionais que atuam nesta disciplina. Os depoimentos dos professores foram examinados a partir de duas categorias de análise: as características das saídas de campo e as concepções sobre a disciplina de Geologia Introdutória. A análise demonstrou que não há diferenças significativas entre os professores no que diz respeito aos trabalhos realizados em campo, independentemente da formação, titulação e instituição onde atuam. As diversas alternativas de trabalhos de campo ainda estão distantes da prática da maioria dos professores, que optam por atividades voltadas ao reconhecimento no campo de conteúdos desenvolvidos em sala de aula. Entretanto, revelaram-se duas concepções distintas quanto ao papel da disciplina no curso e os conteúdos que deve abranger: a visão do professor geólogo e a visão do professor geógrafo. Em que pese tais diferenças, as concepções de ambos os profissionais não são, de modo geral, compatíveis com as características e conteúdos dos trabalhos de campo que promovem.
\end{abstract}

\section{Palavras-chave:}

Geografia, Geologia, trabalhos de campo, ensino.

\section{ABSTRACT}

The research aims at analyzing the activities of field in courses of Introductory Geology in the Geography Schools in the State of the Paraná. The data had been collected by means of interviews with the responsible professors for the course, in the educational institutions that keep the course of Geography in the State. The analysis of the results made possible to characterize the practical one of the professors in the activities of field, since the red tape until the execution, besides evidencing the different visions of education of the different professionals who act in this discipline. The professors ' interviews were examined from two categories of analysis: the features of the field outputs and the conceptions in courses of Introductory Geology. The analysis demonstrated that there aren't significant differences between the two kinds of professors in respect to the works carried through in field, independently of the formation, titulation and institution where they work. The diverse alternatives of field works are still distant from the practical one of the majority of the professors, who choose activities directed to the recognition in the field of contents developed in classroom. However, two conceptions had different views concerning the role of the subject in the Geography course and the contents that it must contain: the vision of both geology and geography professors. In spite of these differences, the conceptions of both the professionals are not, generally speaking, compatible with the features and contents of the field works that promote.

\section{Key-words:}

Geography, Geology, fieldwork, teaching.

1 Geólogo (Unisinos); licenciado em Geografia (UFPR); mestre em Geociências - Área de educação aplicada às geociências Unicamp; doutorando em Ensino e História de Ciências da Terra - Unicamp 


\section{INTRODUÇÃO}

O tema da pesquisa prende-se à questão dos trabalhos de campo na disciplina de Geologia Introdutória nos cursos de Geografia. ${ }^{2}$

A expressão Geologia Introdutória refere-se às disciplinas que "... introduzem a aprendizagem no conhecimento geológico apresentando a estrutura básica desse conhecimento sob uma perspectiva abrangente, que inclui a Geologia como um todo e os principais processos e produtos por ela estudados" (CUNHA, 1986, p. 11). Nos cursos de Geografia no Estado do Paraná, essa disciplina recebe várias denominações: Geologia; Geologia Geral; Geologia aplicada à Geografia; Fundamentos de Geologia e Pedologia; Fundamentos de Geologia, Petrografia e Pedologia. ${ }^{3}$

Os conteúdos básicos da disciplina Geologia Introdutória ${ }^{4}$ são de grande importância para outras disciplinas que se seguem no curso de Geografia, tais como Geomorfologia, Pedologia e Biogeografia, pois a compreensão dos diversos assuntos trabalhados nestas disciplinas dependem, em parte, dos conteúdos vistos na disciplina de Geologia Introdutória. O trabalho de campo nessa disciplina, por sua vez, contribui para a integração entre os aspectos físicos e sociais, o que é fundamental para uma visão global do objeto investigado, visão essa característica da ciência geográfica.

Coelho (1997) salienta o fato de os geógrafos terem uma visão mais global e sintética da realidade. Deste modo, a capacidade de interrelacionar os mais diversos dados demonstraria uma preocupação com o conjunto, não alcançado por especialistas de outras áreas. A autora salienta, ainda, que esta abordagem global vem sendo novamente valorizada nos meios científicos, devido à necessidade de se levarem em consideração os diversos aspectos para uma melhor compreensão da realidade, como um todo.

É neste contexto que os trabalhos de campo no curso de Geografia, em especial na disciplina de Geologia Introdutória, podem fornecer ao futuro geógrafo o necessário contato com essa gama de interações possíveis nos estudos que envolvem os aspectos naturais e sociais, tais como a ação antrópica sobre o meio e as conseqüências dessa intervenção para a sociedade.
É importante ressaltar como as atividades de campo podem contribuir para que os estudantes de períodos iniciais de Geografia, muitas vezes carentes do conhecimento de Física, Química e Biologia, desenvolvam a estrutura básica do raciocínio geológico e a habilidade de aplicar esse tipo de raciocínio na resolução de problemas de natureza geocientífica (FANTINEL, 2000, p. 8).

\section{REVISÃO BIBLIOGRÁFICA}

Compiani e Carneiro (1993, p. 90) classificam as excursões geológicas, ${ }^{5}$ de acordo com seu papel didático. Os autores definem os papéis didáticos como "funções que determinada atividade assume dentro do processo de ensino-aprendizagem, decididas de maneira deliberada ou não, que exercem algum significado para o alcance de objetivos didáticos".

Os autores classificam as saídas de campo em: Ilustrativas, Indutivas, Motivadoras, Treinadoras e Investigativas.

a) Atividade de campo ilustrativa: É considerada a mais tradicional das saídas de campo, pois reafirma o conhecimento como produto acabado. Serve para mostrar ou reforçar os conceitos já vistos em sala de aula. É centrada no professor, que se utiliza da lógica da ciência para reforçar o conteúdo no campo. O aluno faz o papel do espectador com a caderneta de campo repleta de anotações repassadas pelo professor.

b) Atividade de campo indutiva: Este tipo de saída de campo visa "guiar seqüencialmente os processos de observação e interpretação, para que os alunos resolvam um problema dado". O papel do professor é de conduzir os alunos ou fazer com que eles sigam um determinado roteiro de atividades, geralmente acompanhado por questionário envolvendo questões teóricas com conceitos previamente estabelecidos. O ensino é dirigido, podendo chegar a semidirigido, mas é delimitado pelo professor que define o ritmo dos trabalhos. Segundo os autores "o processo de aprendizagem valoriza os métodos científicos e o raciocínio lógico dos alunos, sem preocupar-se com os conhecimentos geológicos prévios".

c) Atividade de campo motivadora: Tem como objetivo despertar o interesse dos alunos para um dado

\footnotetext{
2 O presente artigo trata-se de parte da dissertação de mestrado em Geociências na área de educação aplicada às Geociências, concluído em 2001 na Universidade Estadual de Campinas.

${ }^{3}$ Nesse artigo se utilizará a denominação de "Geologia Introdutória" a essas disciplinas.

${ }^{4}$ Esses conteúdos básicos da disciplina Geologia Introdutória incluem origem da Terra, teoria da tectônica de placas, tempo geológico, rochas e minerais, intemperismo e ação geológica da água, vento, geleiras e organismos.

${ }^{5}$ Compiani \& Carneiro usam a expressão excursões geológicas (EG), neste artigo substituído por trabalhos, atividades ou saídas de campo, sem prejuízo do significado proposto por tais autores.
} 
problema ou aspecto a ser estudado. Este tipo de trabalho é, geralmente, realizado com alunos desprovidos de conhecimentos geológicos anteriores, porque valorizam-se aspectos mais genéricos, como a paisagem, o senso comum e a afetividade com o meio. O objetivo é despertar a curiosidade e o interesse do aluno para a disciplina ou curso. A saída de campo é centrada no aluno, valorizando a experiência de cada um e os seus questionamentos.

d) Atividade de campo treinadora: Visa treinar habilidades, geralmente com o uso de aparelhos, instrumentos ou aparatos científicos. Exige conhecimentos prévios por parte do aluno que fará anotações, medições ou coleta de amostras. As atividades são direcionadas pelo professor, cabendo ao aluno, seguir as recomendações e treinar a técnica ou procedimento.

e) Atividade de campo investigativa: Propicia ao aluno resolver determinados problemas no campo. Os alunos podem elaborar hipóteses a ser pesquisadas; estruturar a seqüência de observação e interpretação; decidir as estratégias para validá-las, inclusive avaliando a necessidade de recorrer à literatura; discutir entre si as reflexões e conclusões.

$\mathrm{Na}$ atividade de campo investigativa o papel do professor é o de um orientador que resolve as dúvidas dos alunos quando solicitado, além de incentivá-los, dando o suporte necessário para que os mesmos não se dispersem no assunto a ser trabalhado. O professor pode propor um problema para ser solucionado, o que direciona a atenção dos alunos para o conteúdo. A saída é centrada no aluno e valoriza seus conhecimentos prévios, não se importando muito com a lógica da ciência, pois aqui o professor considera o aluno capaz de desenvolver habilidades no campo teórico.

A partir da experiência do autor como professor da disciplina de Geologia Introdutória para o curso de Geografia, acrescenta-se outro tipo de trabalho de campo, a saída de campo autônoma.

Esta saída objetiva despertar no aluno o seu espírito investigativo e prepará-lo para a sua realidade profissional futura. É realizada, preferencialmente, na região onde os alunos se encontram, em áreas escolhidas por eles e sem a presença do professor. A investigação é constante, cabendo ao professor o papel de orientador. Os alunos retornam ao campo quantas vezes forem necessárias. A relação professor-aluno e aluno-aluno é ampliada pelas contínuas discussões e trocas de experiências.

Compiani (1991, p. 14) considera que o campo pode ser um fio condutor para uma disciplina, propiciando, a partir de uma área de estudo, o entendimento dos principais processos e conceitos desta e o melhor desenvolvimento das peculiaridades da prática científica geológica, e dos respectivos procedimentos mentais. $O$ autor considera que "o campo pode ser gerador de problemas, isto é, uma ótima situação de ensino problematizadora e, também, pode ser agente integrador da Geologia e outras ciências na construção de uma visão abrangente de natureza".

Como exemplo desse processo gerador de problemas, pode-se relatar uma das atividades de campo autônomas realizadas pelo autor deste artigo na disciplina de Geologia Introdutória, em que atua como docente. ${ }^{6} \mathrm{O}$ trabalho é realizado no curso de Geografia, no $1^{\circ}$. ano de licenciatura plena. Ao realizarem trabalhos de campo sobre os principais bens minerais explorados na região metropolitana de Curitiba, ${ }^{7}$ os grupos de alunos percebem vários aspectos, desde os ligados exclusivamente com o bem mineral em estudo até aqueles relacionados ao impacto ambiental, bem como a influência sobre as populações circunvizinhas. Um exemplo desta atividade refere-se à equipe que pesquisou a exploração de areia no ano de 1999 no entorno do município de Araucária na área metropolitana de Curitiba. Ao visitar alguns locais de extração, a equipe observou que, após a exaustão de alguns depósitos, os mesmos eram abandonados pelas empresas concessionárias e, posteriormente, ocupados por grupos socialmente menos favorecidos que utilizavam esses locais para edificar suas moradias gerando um grave problema urbano. Além disso, provocavam um sério problema ambiental, pois estes locais são áreas de mananciais, o que evidenciou, também, um descaso do Poder Público.

Em nenhum momento houve hesitação dos alunos em analisar tanto o bem mineral em exploração quanto a ação antrópica e suas conseqüências. Percebeu-se que a análise, não só do bem mineral estudado, mas a pesquisa no local da extração e a observação dos problemas ambientais gerados é que permitiram aos alunos a realização de um trabalho enriquecedor. Assim, a saída ao campo e a pesquisa de um recurso mineral tornaram-se o fio condutor do trabalho.

A saída de campo autônoma destaca-se pelo fato de o aluno ir ao campo sem a presença do professor, trazendo suas anotações, amostras e imagens que serão trabalhadas em sala de aula. Além disso, apresenta, em relação à saída do tipo investigativa, maior influência na

\footnotetext{
${ }^{6} \mathrm{O}$ autor desta dissertação exerce a docência na Faculdade de Ciências Humanas e Sociais de Curitiba (FACIAUSO).

7 Esta proposta de atividade teve início no curso de especialização em Ensino de Geociências no IG-UNICAMP em 1998. Desde então, este trabalho é realizado com os alunos, na disciplina de Geologia Introdutória, no curso de Geografia da FACIAUSO.
} 
elaboração de dúvidas e questões e no desenvolvimento e exercício de habilidades. ${ }^{8}$

A partir do conjunto de informações trazidas pelos alunos, as discussões se tornam enriquecidas e eles percebem que o seu conhecimento prévio, valorizado pelo professor, é utilizado na construção da própria prática científica.

"é fundamental para o estudante essa noção de conhecimento como um construto da prática científica, do ir e vir à fonte de informações, de testar, reformular, elaborar e adquirir a noção dos limites da produção científica; tudo isso contribui para desmitificar o conhecimento científico e o cientista". (COMPIANI, 1991, p. 13)

A saída de campo autônoma não pode servir como pretexto para o professor se ausentar do campo. Os trabalhos de campo com a presença e orientação do professor são importantes, pois o contato direto com o objeto a ser investigado e os desafios que surgem, ao longo do trabalho, são enriquecidos com sua presença. A saída autônoma tem como objetivo promover uma constante investigação ao longo do curso, onde, além das saídas de campo realizadas oficialmente, os alunos, a partir dos temas que vão sendo abordados em sala de aula, tenham a possibilidade de fazer a interrelação entre a teoria e sua aplicação no cotidiano. A participação de turmas do período noturno, constituídas usualmente por alunos que trabalham durante o dia, fica facilitada nesse tipo de trabalho porque os horários de pesquisa são escolhidos pelos próprios alunos.

Com o acréscimo da nova categoria proposta obtém-se a classificação dos trabalhos de campo utilizada nesta pesquisa (figura 1):

FIGURA 1 - OBJETIVOS DE ENSINO/APRENDIZAGEM NAS EXCURSÕES GEOLÓGICAS

\begin{tabular}{|c|c|c|c|c|c|}
\hline $\begin{array}{c}\text { Categoria } \\
\text { papel }\end{array}$ & $\begin{array}{l}\text { Objetivos } \\
\text { das } \\
\text { atividades }\end{array}$ & $\begin{array}{c}\text { Visão } \\
\text { de } \\
\text { ensino }\end{array}$ & $\begin{array}{l}\text { Modelos } \\
\text { científicos } \\
\text { existentes }\end{array}$ & $\begin{array}{c}\text { Relação } \\
\text { de ensino/ } \\
\text { aprendizagem }\end{array}$ & $\begin{array}{l}\text { Lógica } \\
\text { predominante }\end{array}$ \\
\hline Ilustrativa & & Informativa & $\begin{array}{l}\text { São aceitos e } \\
\text { preservados }\end{array}$ & $\begin{array}{l}\text { Professor é o } \\
\text { centro } \\
\text { Ensino dirigido }\end{array}$ & Da ciência \\
\hline Indutiva & & $\begin{array}{l}\text { Formativa/ } \\
\text { Informativa }\end{array}$ & $\begin{array}{l}\text { São aceitos e } \\
\text { preservados }\end{array}$ & $\begin{array}{l}\text { Aluno é o centro } \\
\text { Ensino dirigido/ } \\
\text { semi dirigido }\end{array}$ & $\begin{array}{l}\text { Da ciência e } \\
\text { do aprendiz }\end{array}$ \\
\hline Motivadora & & Formativa & $\begin{array}{c}\text { São aceitos e } \\
\text { preservados, em } \\
\text { grau variável }\end{array}$ & $\begin{array}{l}\text { Aluno é o centro } \\
\text { Ensino não dirigido }\end{array}$ & Do aprendiz \\
\hline Treinadora & & $\begin{array}{l}\text { Formativa/ } \\
\text { Informativa }\end{array}$ & $\begin{array}{l}\text { São aceitos e } \\
\text { preservados }\end{array}$ & $\begin{array}{l}\text { Equilíbrio } \\
\text { Ensino semi } \\
\text { dirigido }\end{array}$ & $\begin{array}{c}\text { Da ciência e às } \\
\text { vezes do aprendiz }\end{array}$ \\
\hline Investigativa & & Formativa & $\begin{array}{l}\text { São aceitos, } \\
\text { mas } \\
\text { questionados }\end{array}$ & $\begin{array}{l}\text { Aluno é o centro } \\
\text { Ensino não dirigido }\end{array}$ & $\begin{array}{l}\text { Da ciência e } \\
\text { do aprendiz }\end{array}$ \\
\hline Autônoma & & Formativa & $\begin{array}{l}\text { São aceitos, } \\
\text { mas } \\
\text { questionados }\end{array}$ & $\begin{array}{l}\text { Aluno é o centro } \\
\text { Ensino não dirigido }\end{array}$ & $\begin{array}{l}\text { Da ciência e } \\
\text { do aprendiz }\end{array}$ \\
\hline
\end{tabular}

OBJETIVOS DAS ATIVIDADES

\begin{tabular}{|l|l|}
\hline $\begin{array}{l}\text { Aproveitar os conheci- } \\
\text { mentos geológicos } \\
\text { prévios }\end{array}$ & $\begin{array}{l}\text { Reconhecer feições } \\
\text { e fenômenos da } \\
\text { natureza }\end{array}$ \\
\hline $\begin{array}{l}\text { Elaborar dúvidas e } \\
\text { questões }\end{array}$ & $\begin{array}{l}\text { Desenvolver e exercitar } \\
\text { habilidades }\end{array}$ \\
\hline $\begin{array}{l}\text { Estruturar hipóteses/ } \\
\text { sínteses e criar } \\
\text { conhecimento }\end{array}$ & $\begin{array}{l}\text { Desenvolver } \\
\text { atitudes e valores }\end{array}$ \\
\hline
\end{tabular}

INFLUÊNCIA DOS OBJETIVOS

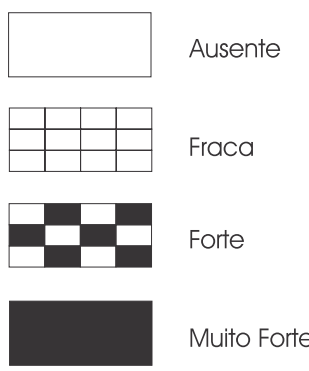

FONTE:

COMPIANI \& CARNEIRO (1993), COM ACRÉSCIMOS.

${ }^{8}$ Elaboração de dúvidas e questões e desenvolvimento e exercício de habilidades estão entre os seis objetivos das atividades na classificação de Compiani e Carneiro (1993). 
QUADRO 1 - CURSOS DE GEOGRAFIANO ESTADO DO PARANÁ

\begin{tabular}{|c|c|c|}
\hline INSTITUIÇÃO & CURSO & CIDADE \\
\hline UFPR & Bacharelado/Licenciatura & Curitiba \\
\hline UTP & Bacharelado/Licenciatura & Curitiba \\
\hline FACIAUSO & Licenciatura & Curitiba \\
\hline UEL & Bacharelado/Licenciatura & Maringá \\
\hline UEM & Bacharelado/Licenciatura & Ponta Grossa \\
\hline UEPG & Bacharelado/Licenciatura & Guarapuava \\
\hline UNICENTRO & Licenciatura & Mar. Când. Rondon \\
\hline UNIOESTE & Licenciatura & Francisco Beltrão \\
\hline UNIOESTE & Bacharelado/Licenciatura & Jandaia do Sul \\
\hline FAFIJAN & Licenciatura & União da Vitória \\
\hline FAFI & Licenciatura & Cornélio Procópio \\
\hline FAFICOP & Licenciatura & Paranavaí \\
\hline FAFIPA & Licenciatura & Campo Mourão \\
\hline FECILCAM & Licenciatura & \\
\hline
\end{tabular}

FONTE: PESQUISA DE CAMPO.

ESTADO DO PARANÁ / 1999 (SCORTE GAGNA, 2001)

\section{MATERIAIS E MÉTODOS}

\section{UNIVERSO PESQUISADO}

O universo da pesquisa compõe-se de quatorze instituições de ensino superior no Estado do Paraná que oferecem o curso de Geografia (licenciatura plena e/ou bacharelado).

Entrevistaram-se os professores titulares da disciplina de Geologia Introdutória nos cursos de Geografia. Foram entrevistados apenas treze professores, pois em uma das instituições, o autor deste trabalho é o responsável pela disciplina de Geologia Introdutória.

\section{INSTRUMENTO DE PESQUISA}

A pesquisa realizou-se através de entrevistas semiestruturadas, pois "se desenrola a partir de um esquema básico, porém não aplicado rigidamente, permitindo que o entrevistador faça as necessárias adaptações" (LÜDKE \& MARLI, 1986, p. 34).

Os tópicos selecionados para análise foram os seguintes: (1) Características das saídas de campo, que abrangem um conjunto de quatro características: a) $O$ momento ideal da saída de campo; b) Tipos de saída de campo; c) Conteúdos trabalhados no campo; d) Preparação do aluno para a saída de campo.
O outro tópico selecionado, (2) Concepções sobre a disciplina de Geologia Introdutória - a visão do geólogo e a visão do geógrafo, é dividida em três subtópicos: a) Papel da disciplina no curso de Geografia; b) Conteúdos fundamentais para o futuro geógrafo; c) Articulação dos conteúdos geológicos e geográficos (SCORTEGAGNA, 2001).

\section{RESULTADOS DA PESQUISA}

\section{CARACTERIZAÇÃO DA DISCIPLINA E PROFESSORES QUEAMINISTRAM}

O quadro a seguir (quadro 2) apresenta uma visão geral da formação dos professores entrevistados, além de informações referentes às instituições em que atuam e à disciplina de Geologia Introdutória oferecida nessas instituições.

No Estado do Paraná há 14 instituições de ensino superior que mantêm cursos de Geografia. Desse total, apenas 3 instituições são particulares; há 6 universidades estaduais; 1 universidade federal e 4 faculdades estaduais isoladas.

Do total de 14 instituições, apenas três localizam-se na capital. As demais localizam-se no interior do Estado, sendo que a cidade mais próxima de Curitiba com curso de Geografia é Ponta Grossa, a uma distância de 
QUADRO 2 - IDENTIFICAÇÃO DOS PROFESSORES E RESPECTIVAS INSTITUIÇÕES DE ENSINO

\begin{tabular}{|c|c|c|c|c|c|c|c|}
\hline & Instituição & Curso & Sexo & $\begin{array}{c}\text { Graduação do } \\
\text { professor }\end{array}$ & $\begin{array}{l}\text { Origem da } \\
\text { graduação }\end{array}$ & Titulação & $\begin{array}{l}\text { Carga horária da } \\
\text { disciplina }\end{array}$ \\
\hline UFPR & $\begin{array}{l}\text { Universidade } \\
\text { Pública }\end{array}$ & $B / L$ & M & Geologia & São Paulo & Mestrado & $60 \mathrm{~h} / \mathrm{a} \mathrm{s} /$ pedologia \\
\hline UEL & $\begin{array}{l}\text { Universidade } \\
\text { Pública }\end{array}$ & $B / L$ & $M$ & Geologia & Paraná & Mestrado & $150 \mathrm{~h} / \mathrm{a}$ s/ pedologia \\
\hline UEM & $\begin{array}{l}\text { Universidade } \\
\text { Pública }\end{array}$ & $B / L$ & M & Geologia & São Paulo & Pós-Doutorado & 120 h/a s/ pedologia \\
\hline UEPG & $\begin{array}{l}\text { Universidade } \\
\text { Pública }\end{array}$ & $B / L$ & M & Geologia & São Paulo & Doutorado & $120 \mathrm{~h} / \mathrm{a} \mathrm{c} /$ pedologia \\
\hline UNICENTRO & $\begin{array}{l}\text { Universidade } \\
\text { Pública }\end{array}$ & L & $\mathrm{M}$ & $\begin{array}{l}\text { Geografia - } \\
\text { B/L }\end{array}$ & Paraná & Mestrado & $90 \mathrm{~h} / \mathrm{a} \mathrm{c} /$ pedologia \\
\hline UNIOESTE & $\begin{array}{l}\text { Universidade } \\
\text { Pública }\end{array}$ & L & M & Geologia & Paraguai & Doutorado & $60 \mathrm{~h} / \mathrm{a} \mathrm{s} /$ pedologia \\
\hline UNIOESTE & $\begin{array}{l}\text { Universidade } \\
\text { Pública }\end{array}$ & $B / L$ & $F$ & $\begin{array}{l}\text { Geografia - } \\
\text { B/L }\end{array}$ & São Paulo & Mestrado & $120 \mathrm{~h} / \mathrm{a} \mathrm{c} /$ pedologia \\
\hline FAFIPA & $\begin{array}{l}\text { Faculdade } \\
\text { Pública }\end{array}$ & L & $F$ & Geografia - L & Paraná & Especialização & $120 \mathrm{~h} / \mathrm{a}$ s/ pedologia \\
\hline FAFICOP & $\begin{array}{l}\text { Faculdade } \\
\text { Pública }\end{array}$ & L & M & $\begin{array}{l}\text { Geografia - } \\
B / L\end{array}$ & Paraná & Especialização & $120 \mathrm{~h} / \mathrm{a} \mathrm{c} /$ pedologia \\
\hline FECILCAM & $\begin{array}{l}\text { Faculdade } \\
\text { Pública }\end{array}$ & L & M & Geografia - L & Paraná & Especialização & $120 \mathrm{~h} / \mathrm{a}$ s/ pedologia \\
\hline FAFI & $\begin{array}{l}\text { Faculdade } \\
\text { Pública }\end{array}$ & $\mathrm{L}$ & M & Geografia - L & Paraná & Especialização & $90 \mathrm{~h} / \mathrm{a} \quad \mathrm{c} /$ pedologia \\
\hline FAFIJAN & $\begin{array}{l}\text { Faculdade } \\
\text { Particular }\end{array}$ & L & $F$ & Geografia - L & Paraná & Especialização & $150 \mathrm{~h} / \mathrm{a} \mathrm{c} /$ pedologia \\
\hline UTP & $\begin{array}{l}\text { Universidade } \\
\text { Particular }\end{array}$ & $B / L$ & $M$ & Agronomia & Paraná & Doutorado & $60 \mathrm{~h} / \mathrm{a} \mathrm{c} /$ pedologia \\
\hline FACIAUSO & $\begin{array}{l}\text { Faculdade } \\
\text { Particular }\end{array}$ & L & M & Geologia & $\begin{array}{l}\text { Rio Grande } \\
\text { do Sul }\end{array}$ & Especialização & $60 \mathrm{~h} / \mathrm{a} \mathrm{c} /$ pedologia \\
\hline
\end{tabular}

FONTE: PESQUISA DE CAMPO.

PARANÁ, 1999 (SCORTEGAGNA, 2001)

B/L: BACHARELADO E LICENCIATURA

L: LICENCIATURA

aproximadamente $100 \mathrm{~km}$. Há uma concentração maior dos cursos de Geografia no Norte/Noroeste do Estado, região sob influência das cidades de Londrina e Maringá. Nesta região encontram-se sete instituições.

A formação em Geografia voltada exclusivamente para licenciatura é predominante: oito das instituições (57\%) sendo seis delas faculdades isoladas, públicas ou particulares. O restante das instituições, que representam $43 \%$, mantém Bacharelado e Licenciatura. Essa dupla formação é oferecida exclusivamente nas universidades, uma delas particular.
Percebe-se a predominância de profissionais do sexo masculino na disciplina de Geologia Introdutória (79 \% das instituições). Apenas três mulheres, representando $21 \%$, todas com formação em Geografia, ministram essa disciplina.

Quanto à origem dos professores, percebe-se que 57 \% são formados no Estado do Paraná, mas a influência do Estado de São Paulo é grande. Professores formados nesse Estado são responsáveis pela disciplina em 29 \% das instituições, todas universidades públicas. Estes professores caracterizam-se por terem mestrado ou doutorado. 
Com referência à formação dos professores da disciplina de Geologia Introdutória, observou-se que $50 \%$ são formados em Geografia e, à exceção de uma professora, em instituições do Paraná. Dos sete geógrafos, cinco fizeram cursos de especialização e atuam em instituições de pequeno porte, públicas ou particulares. Apenas dois desses profissionais têm mestrado. Quanto aos professores geólogos, atingem $43 \%$ do total e, à exceção de um professor, são formados em instituições fora do Estado. Dos seis geólogos, cinco têm doutorado ou mestrado e atuam em universidades públicas.

Nota-se que os professores(as) geógrafos(as) e geólogos constituem dois grupos bastante distintos quanto à origem, titulação e instituição em que trabalham. Mas essa distinção não surpreende. A amplitude das universidades implica disponibilidade de profissionais especializados e titulados, daí congregarem a maior parte dos geólogos. Além de não contarem com essa disponibilidade, as instituições de pequeno porte mantêm número limitado de alunos, o que restringe o número de horas-aula da disciplina, que acaba ficando a cargo de um profissional da casa, já responsável por outra(s) disciplina(s). Daí congregarem os profissionais geógrafos.

Quanto ao exercício de outra atividade profissional, a quase totalidade dos professores entrevistados exerce apenas a função de docente. Dos quatorze professores, apenas um exerce outra atividade.

A carga horária da disciplina de Geologia Introdutória varia de 60 até 150 horas/aula. Considerou-se, para cálculo, a carga horária semanal informada pelos professores, verificando-se quatro níveis: $60,90,120$ e 150 horas/ aula, equivalendo a 2, 3, 4 e 5 horas semanais, respectivamente. Em algumas instituições o conteúdo de solos está incluído na disciplina de Geologia Introdutória e, em outras, este conteúdo é direcionado a outra disciplina denominada "Pedologia".

A disciplina de Geologia Introdutória é trabalhada no curso de Geografia, no $1^{\circ}$ ano, com exceção de uma instituição, onde é lecionada no $2^{\circ}$ ano do curso. A disciplina é anual, com exceção de uma instituição, onde é semestral.

\section{CARACTERÍSTICAS DAS SAÍDAS DE CAMPO}

Das treze instituições analisadas, apenas em duas não há trabalhos de campo vinculados à disciplina de Geologia Introdutória (quadro 3).

Os fatores "tempo" e "custo" fazem com que diversos professores realizem suas saídas de campo na região onde a instituição se localiza, e com duração de um dia apenas. Excursões com retorno no mesmo dia evitam despesas de hotel, diária do motorista, principalmente em instituições de ensino privadas, onde o aluno arca com a maior parte das despesas de trabalhos de campo.

O depoimento dos professores, na entrevista semiestruturada, permitiu analisar as saídas de campo segundo as quatro características selecionadas: 1) Momento ideal da saída de campo; 2) Tipos de saída de campo; 3) Conteúdos trabalhados no campo; 4) Preparação do aluno para a saída de campo.

1. Momento ideal da saída de campo: O momento em que a saída de campo é realizada independe da formação ou titulação do professor ou da instituição à qual está vinculado, pois a quase totalidade opta por realizar suas saídas somente após o conteúdo lecionado. Esta prática, possivelmente, está associada a uma abordagem tradicional do processo de ensino.

\begin{abstract}
"Evidencia-se uma preocupação com a sistematização dos conhecimentos apresentados de forma acabada. As tarefas de aprendizagem quase sempre são padronizadas, o que implica poder recorrer-se à rotina para se conseguir a fixação de conhecimentos/ conteúdos/informações." (MIZUKAMI, 1986, p. 14)
\end{abstract}

Compiani e Carneiro (1993) colocam em dúvida a noção de que o pensamento reflexivo só tem lugar após um certo acúmulo de informações. Para estes autores, as atividades de campo podem ser realizadas antes dos preceitos teóricos, pois facilitam uma aprendizagem construtivista.

2. Tipos de saída de Campo: nas onze instituições que realizam saídas de campo específicas da disciplina, predominam as saídas do tipo ilustrativas, o que é coerente com a preferência dos professores por saídas, após o conteúdo trabalhado em sala de aula, como foi visto no item anterior. Este tipo de saída de campo serve para mostrar ou reforçar os conceitos já estudados em sala de aula. É centrada no professor, e seu conteúdo utilizase amplamente da lógica da ciência. O professor reafirma

QUADRO 3 - NÚMERO DE SAÍDAS DE CAMPO REALIZADAS NA DISCIPLINA

\begin{tabular}{|c|c|}
\hline Saídas de campo & $\mathbf{N}^{\circ}$ de instituições \\
\hline Não há & 2 \\
\hline 01 & 1 \\
\hline 02 & 5 \\
\hline 03 ou mais & 5 \\
\hline
\end{tabular}

FONTE: PESQUISA DE CAMPO: ESTADO DO PARANÁ/1999 (SCORTEGAGNA, 2001) 
o conhecimento como produto acabado e inquestionável.

O aluno desempenha o papel de espectador, podendo fazer alguns questionamentos ao professor, e com freqüência é incumbido de elaborar esquemas ilustrativos do objeto de estudo, como "afloramentos", por exemplo.

Percebe-se um ensino centrado no professor. A abordagem de ensino tradicional prevalece, pois "privilegiam-se o especialista, os modelos e o professor, elemento imprescindível na transmissão do conhecimento" (MIZUKAMI, 1986:8). O professor parece desconsiderar o conhecimento trazido pelo aluno, valorizando o conhecimento teórico, visto em sala de aula e sua confirmação no campo. A intenção do professor é utilizar o campo como instrumento para relembrar, reforçar e ilustrar o conteúdo estudado em sala de aula. É uma forma de confirmar o que o professor expôs em aula.

Paschoale (1984) questiona as saídas do tipo ilustrativas observando que ocorre uma maior valorização da representação do objeto investigado, ao invés do real, observado diretamente no campo. O autor (1984:5248???) observa que "aprender Geologia é fazer Geologia e não aprender seus enunciados, quer sejam definições, desenhos, diagramas ou teorias".

3. Conteúdos trabalhados no campo: constata-se que, independentemente da formação, titulação e instituição onde o professor atua, há uma preferência por "rochas e minerais", tema fundamental em Geologia. A articulação com a esfera social e mesmo a abordagem de outros aspectos físicos, ligados a Geografia, não são tratados ou ficam em segundo plano. Uma especulação da origem desse procedimento é que os programas da mesma disciplina nos cursos de Geologia são transplantados ipsis literis para os cursos de Geografia, sem sequer uma adequação aos novos objetivos.

4. Preparação do aluno para a saída de campo: constata-se que a preferência dos professores em preparar os alunos para a saída de campo independe de formação, titulação e instituição onde atuam, pois a totalidade considera importante que o aluno vá ao campo sabendo o que vai encontrar. Essa tendência já foi observada quando se examinou o momento escolhido pelos professores para a saída.

Misukami (1986) observa que, na abordagem tradicional de ensino, o professor considera que houve aprendizagem quando há a reprodução dos conteúdos realizadas pelo aluno, de forma automática e sem variações. Portanto ao preparar o aluno para a saída de campo, o professor demonstra estar preocupado com que o aluno reproduza, no campo, o conteúdo visto em sala de aula. Para o professor isto significa aprendizagem.

Nos depoimentos, destaca-se a preocupação dos professores em preservar o aluno do impacto do novo, do choque. A entrega do roteiro de campo, com os conteúdos a serem trabalhados, encontram-se em sintonia com uma abordagem tradicional do processo de ensino, como visto anteriormente.

\section{A VISÃO DO GEÓLOGO E A VISÃO DO GEÓGRAFO}

Constatou-se que o perfil dos professores da disciplina Geologia Introdutória formados em Geologia é bastante distinto do dos formados em Geografia. Enquanto os professores geólogos, na grande maioria, possuem titulação e trabalham em universidades públicas, a maioria dos professores geógrafos fez pósgraduação latu sensu e leciona em instituições de pequeno porte. Entretanto, do ponto de vista das saídas de campo, seus procedimentos e concepções são muito semelhantes, ao menos no âmbito da categoria analisada.

No que se refere ao papel da disciplina de Geologia Introdutória no curso de Geografia observou-se que os professores geólogos, possivelmente em função de sua formação técnica, buscam a aplicabilidade do conhecimento transmitido aos alunos. Entre os professores geógrafos há também a preocupação com a aplicação do conhecimento adquirido, mas direcionado ao campo acadêmico, na sua relação com a sala de aula e sua prática, enquanto professor.

Por conseguinte, percebe-se uma diferença entre os dois profissionais que, possivelmente, esteja vinculada à sua formação. Os geólogos tendem a ter uma visão aplicativa do conhecimento, uma visão prática; já os geógrafos apresentam uma visão teórica sem um vínculo claro com a realidade a ser enfrentada pelo aluno. A preocupação reside na sua prática enquanto professor e na inserção da disciplina no campo teórico da Geografia.

Os resultados indicam que os depoimentos dos professores são compatíveis com a respectiva formação. Os professores geólogos revelam uma postura técnica, aplicada, enquanto os geógrafos se voltam mais para a teoria. Do ponto de vista de visão científica, os geólogos manifestam com mais clareza as articulações entre as duas ciências.

Em relação aos conteúdos considerados mais importantes para o futuro profissional da Geografia, observaram-se algumas tendências. Entre os professores geólogos há uma preferência por conteúdos associados à "dinâmica da Terra"; "processos exógenos"; "pedologia" além de "rochas e minerais". O que chama a atenção neste grupo é, novamente, a preocupação em relação ao conteúdo lecionado e sua aplicação, na atividade profissional do futuro geógrafo.

Entre os professores geógrafos há preferência por rochas e minerais, além de conteúdos ligados ao meio 
ambiente, geologia regional e processos exógenos. Não se percebe na maioria deste grupo, uma preocupação espontânea com a associação entre o conteúdo e a atividade profissional do futuro geógrafo.

Verifica-se incoerência no procedimento da maioria dos professores, tanto geógrafos quanto geólogos, que privilegiam o conteúdo "rochas e minerais" nas saídas de campo mas consideram mais importantes outros conteúdos. Este fato pode estar associado à tradição: os professores seguem ementas e programas préestabelecidos da disciplina ou, mesmo, programas de livros tradicionais de Geologia Geral. Uma decorrência disso é que os temas regionais não recebem destaque, ou nem mesmo são abordados.

Referente à articulação dos conteúdos geológicos e geográficos observou-se que os professores geólogos tendem a articular os conteúdos da disciplina de Geologia Introdutória com a Geografia, apoiados na utilização destes conteúdos, na atividade profissional do geógrafo. Já entre os professores geógrafos, predomina uma visão teórica referente à articulação dessas duas ciências, ficando no campo epistemológico, na questão espacial.

\section{CONSIDERAÇÕES FINAIS}

Este trabalho permitiu ao autor aprofundar o conhecimento referente ao ensino de Geologia, em especial nos trabalhos de campo, bem como à prática dos professores da disciplina de Geologia Introdutória, no Curso de Geografia. As diversas possibilidades de trabalhos de campo parecem ainda estar distantes da prática da maioria dos professores, que optam por atividades ilustrativas, influenciados pela própria formação. As atividades desse tipo têm importância didática, mas outras formas de pensar o campo podem fazer parte do cotidiano desses professores.

Entre os professores da disciplina de Geologia Introdutória entrevistados, há um consenso de que as atividades de campo são fundamentais no processo ensino-aprendizagem em Geografia. Não obstante, esses professores apresentam, em sua maioria, uma visão ainda tradicional de ensino nos trabalhos de campo, colocandose como centro das atividades, dando poucas oportunidades para o aluno desenvolver seu raciocínio, suas investigações e desconsiderando os seus conhecimentos prévios. Deste modo, a formação do professor e sua titulação não determinaram diferentes maneiras de agir, já que a totalidade dos professores desenvolve atividades de campo de uma forma muito semelhante. Tais procedimentos refletem uma abordagem tradicional do processo de ensino.
A visão de ensino tradicional dos professores é comprovada neste trabalho quando observa-se:

a) A preferência em realizar as saídas de campo após o conteúdo visto em sala de aula;

b) As saídas de campo ilustrativas, onde o professor exerce papel centralizador e o alunos comportam-se como espectadores;

c) A predominância do tema "rochas e minerais" nas saídas de campo, em detrimento de outros aspectos naturais;

d) A preparação do aluno para a saída, demonstrando a preocupação que o aluno confirme no campo o que aprendeu em sala de aula.

Se na prática de campo houve semelhanças entre os professores, puderam-se evidenciar duas visões distintas quanto ao modo de pensar a disciplina e seu papel no curso: a visão do professor geólogo que busca associar o conteúdo à realidade do futuro profissional geógrafo, mas espontaneamente, não manifesta preocupação com o futuro professor de Geografia; e a visão do professor geógrafo, que transpõe para a disciplina os conceitos da ciência geográfica, o espaço, a relação sociedade-natureza, ao mesmo tempo que valoriza a sua própria prática enquanto professor. geógrafos

As diferenças entre os profissionais geólogos e

1. A preocupação maior dos professores, principalmente os geólogos, que são em sua totalidade mestres ou doutores, é com o bacharelado em detrimento da licenciatura. Em seus depoimentos, a quase totalidade dos professores, não manifestaram espontaneamente a preocupação com o futuro professor de Geografia;

2. Os geólogos são práticos e vêem no aluno o futuro profissional. Já os geógrafos apresentam uma preocupação mais relacionada aos objetivos da Geografia, entre eles a relação sociedade-natureza, paisagem e espaço.

Não obstante, existem também semelhanças:

1. Os papéis de professor e aluno referem-se, principalmente, aos aspectos de transmissor e receptor de informações;

2. A finalidade da saída de campo é verificar o conhecimento que foi transmitido em sala de aula;

3. O professor prepara o aluno para a saída de campo fornecendo-lhe os subsídios necessários para que, ao chegar no campo, já tenha alguma noção do que vai encontrar;

4. A visão, por parte do professor, em relação ao conteúdo fundamental para o aluno, não é compatível quanto ao conteúdo trabalhado em campo. 
Os fatos anteriormente descritos demonstram a importância dos trabalhos de campo e, mais ainda, a importância de um trabalho de campo centrado no aluno, bem como na construção do seu conhecimento - portanto um trabalho de campo investigativo. Pode-se considerar que trabalhos de campo sem investigação confundemse com informação, sem grandes transformações na abordagem tradicional do processo de ensino.

Esta postura tradicional dos professores, asso-ciada a um trabalho individual nas suas respectivas disciplinas, prejudica o aluno, que deve juntar os diferentes conteúdos das várias disciplinas e fazer as interrelações. Nos depoimentos dos professores, percebeu-se a dificuldade de interrelação entre os diferentes campos de conhecimento da Geografia, predominando o conhecimento compartimentado, principalmente nas universidades públicas, onde a estrutura é mais complexa e predominam profissionais titulados.

\section{REFERÊNCIAS}

COELHO, A. M. S. Para uma caracterização do raciocínio geográfico. Belo Horizonte, 1997. 152 f. Dissertação (Mestrado em Geografia) - Instituto de Geociências, UFMG.

COMPIANI, M. O fazer geologia com ênfase no campo na formação de professores de ciências para o $1^{\circ} \mathrm{grau}\left(5^{\circ}\right.$ a $8^{\circ}$ séries). Campinas, 1998. 238 f. Dissertação (Mestrado em Educação) - Faculdade de Educação, Universidade Estadual de Campinas.

A relevância das atividades de campo no ensino de geologia na formação de professores de ciências. Cadernos do IG/Unicamp, Campinas, v. 1, n. 2, 1991. p. 2-25.

COMPIANI, M.; CARNEIRO, C. D. R. Os papéis didáticos das excursões geológicas. Enseñanza de las Ciências de la Tierra, v. 1, n. 2, 1993. p. 90-98.

COMPIANI, M.; GONÇALVES, P. W. Aspectos didáticos e metodológicos de uma experiência de introdução dos alunos às atividades de campo em geologia. In: CONGRESSO BRASILEIRO DE GEOLOGIA, 33., 1984, Rio de Janeiro. Anais... Rio de Janeiro: SBG, 1984. p. 5185-5197.

CUNHA, C. A .L. A geologia introdutória nos livros didáticos no Brasil: um estudo da coerência interna dos textos através do conceito de geossinclinal. Campinas, 1986. $207 \mathrm{f}$.
As entrevistas demonstraram que o geólogo apresenta algumas vantagens ao lecionar a disciplina de Geologia Introdutória, principalmente no que se refere ao conhecimento do conteúdo e sua relação com a atividade profissional do geógrafo. Mas, quando se analisam o incremento à interdisciplinaridade e a valorização da atividade docente do futuro geógrafo, o professor geólogo demonstra carências. Nestes aspectos, os geógrafos apresentam uma visão mais lúcida. Portanto, um dos desafios que a ciência geológica deve transpor é a necessidade de se discutir a inserção de disciplinas pedagógicas e humanísticas nos cursos de Geologia.

A disciplina carece de reflexão e reformulação na maioria das instituições. Tal reformulação deverá contar com a participação de ambos os profissionais, geólogos e geógrafos, que juntos podem discutir os problemas relacionados à disciplina e buscar soluções que permitam uma maior integração entre as duas ciências.

Dissertação (Mestrado em Educação) - Faculdade de Educação, Universidade Estadual de Campinas.

FANTINEL, L. M. Práticas de campo em geologia introdutória: papel das atividades de campo no ensino de fundamentos de geologia do curso de geografia. Campinas, 2000. $124 \mathrm{f}$. Dissertação (Mestrado em Educação Aplicada às Geociências) - Instituto de Geociências, Universidade Estadual de Campinas.

MIZUKAMI, M. G. N. Ensino: as abordagens do processo. São Paulo: EPU, 1986. 119 p.

NEWERLA, V. B. Roteiros didáticos e o seu papel nos trabalhos de campo. Campinas, 1997. 32 f. Trabalho de monografia (Disciplina Práticas de Campo no Ensino de Ciências Naturais) - IG/Unicamp.

PASCHOALE, C. Alice no país da geologia e o que ela encontrou lá. In: CONGRESSO BRASILEIRO DE GEOLOGIA, 33., 1984, Rio de Janeiro. Anais... Rio de Janeiro: SBG, 1984. p. $5242-5249$.

SCORTEGAGNA, A. Trabalhos de campo nas disciplinas de Geologia Introdutória: cursos de Geografia no Estado do Paraná. Campinas, 2001. 122 f. Dissertação (Mestrado em Educação Aplicada às Geociências) - Instituto de Geociências, Universidade Estadual de Campinas. 